\title{
Editorial
}

\section{MALARIA - DIAGNOSTICS TODAY}

\author{
Lt Col YOGESH CHANDER*, Col A NAGENDRA ${ }^{+}$, \\ Gp Capt H SUBRAMANYA ${ }^{\#}$
}

MJAFI 2001; 57 : 185-187

KEY WORDS: Malaria diagnostics; Peripheral blood smear (PBS); Quantitative buffy coat (QBC); Polymerase chain reaction (PCR).

\begin{abstract}
Plasmodium has a lot in store
And works in stages by the score

Anopheles that probe your skin

Pumps many sporozoites in
\end{abstract}

\section{The Ballad of the Plasmodium \\ (Leonard Bruce-Chwatt)}

Malaria is one of the oldest recorded diseases in the world and finds mention in Hindi and Chinese writings of more than three thousand years ago. Herbal medicinal extract from the plant Artemesia annua for medication of malaria was known to the Chinese then [1]. Hippocrates in $5^{\text {th }}$ century was first to describe in detail the clinical picture and some complications of the disease. The Peruvian bark tree, the Cinchona, with Quinine as an active principle used for treatment for malaria was discovered in the $17^{\text {th }}$ century much before the causative agent was known. Laveran, a French army surgeon in Algeria first saw and described malarial parasite in RBCs of human beings. The final elucidation of actual mode of transmission came in 1897 when Ronald Ross discovered the mosquito cycle of malarial parasite [2].

Amongst all infectious diseases, malaria continues to be one of the biggest contributors to disease burdens in terms of mortality and morbidity. Malaria is endemic in 91 countries with about $40 \%$ of the world population at risk. Each year there are 300-500 million clinical cases of malaria, $90 \%$ of them in Africa [3] and between 1.5 million and 2.7 million deaths. Many countries in Africa faced severe unprecedented epidemics during the last decade like Botswana, Burundi, Ethiopia, Namibia, Revanda and Zambia [4].

In India, National Malaria Control Program (NMCP) brought the annual incidence of 75 million cases of malaria with 8 lac deaths in 1953 down to 2 million cases in 1958 [3]. National Malaria Eradication Program (NMEP) adopted in 1958 received a major set back due to insecticide resistant strains of mosquito vector and anti-malarial resistant strain of Plasmodium species. The annual incidence of malaria rose to 6.4 million in 1976 [3]. In 1977 NMEP was given up and Modified plan of Operation (MOP) was commenced, results of which brought down the annual incidence to 2.1 million in 1984 [5] and since 1995, the incidence has reached a plateau with 2.8 million cases. The entire population of India is now deemed to be under risk of malaria [6].

Recent data suggest malaria killing between 1.5 and 2.7 million people each year, an average of one person, often a child aged 5 years, every $12 \mathrm{sec}$. In addition to these high numbers of malaria attributable fatalities, it is thought that an additional $300-500$ million people contract the disease each year with unmeasured impact on local economies, human health and longevity [7].

Accurate diagnosis is the corner stone for proper management of malaria and to prevent complications. Malaria, diagnosed on the basis of clinical symptoms is at best $50 \%$ accurate [8]. Therefore the role of the laboratory is to give precise and rapid diagnosis. Direct detection of malarial parasite by microscopy remains the mainstay of diagnosis and is still the gold standard for diagnosis of malaria. This technique is simple, reproducible and cost effective. Giemsa stained, thin and thick peripheral blood smears are examined for malarial parasite. Thick smear provides the sensitivity to the technique and thin smear gives specificity being much better than the thick smear for species identification and evaluation of the intensity of the parasitemia [9]. This technique has undergone

*Reader, ${ }^{+}$Professor and Head, Department of Microbiology; " Professor and Head, Department of Pathology; Armed Forces Medical College, Pune 411040. 
very little improvement since its development in early 1900 s. Although considered a gold standard, diagnosis of malaria using this method can be unsatisfactory, since.it takes upto 60 minutes of preparation time and sample may not be collected timely during the febrile phase all the time. It is labour intensive and interpretation of the results requires considerable expertise, particularly at low levels of parasitemia [10]. In addition, in patients with Plasmodium falciparum malaria, the parasites can be sequestrated and are not always present in peripheral blood. Thus a Plasmodium falciparum infection may be easily missed because there are no parasites in blood smears. Additionally processing and reading large number of blood smears during a malarial outbreak increases the room for error dramatically [9]. Recognizing these limitations, alternate techniques for the diagnosis of malaria have been developed.

Three fluorescent techniques hold promise for the diagnosis of malaria, Quantitative Buffy Coat Assay (QBC Method) [11-14] which is available as a commercial kit, Kawamoto Acridine orange process [1316] and Benzothiocarboxypurine (BCP) procedure [17-18]. These three techniques are rapid and relatively easy to perform and demonstrate sensitivity and specificity equivalent to that achievable by examination of stained thick smear. QBC and Kawamoto methods use Acridine orange (AO) as fluorochrome to stain the nucleic acid of the malarial parasite. BCP is also a fluorochrome, which stains nucleic acids.

The QBC assay is based on the centrifugal stratification of parasitised RBCs in 55-65 $\mu$ l of whole blood in the $\mathrm{QBC}$ capillary tube and staining of parasite DNA and cytoplasm with Acridine orange coated in the tube. This greatly enhances their visibility at the concentrated zone under the ParaLens UV microscope system (Becton Dickinson India Pvt Ltd). AO Staining of thin and thick smear is simple. A drop AO is placed on the thin methanol fixed blood smear. Keep the coverslip over it and examine the slide under UV illumination. For BCP staining equal volume of whole blood $(10 \mu \mathrm{l})$ and BCP dye are taken on the slide, allow to stain for $2 \mathrm{~min}$ and examine the slide under fluorescent microscope. With the fluorochrome dyes the parasitic DNA fluoresce greenish and cytoplasm appears pinkish.

$A O$ is a very intense fluorescent stain and stains nucleic acid of all cell types. Important limitation of methods based on $A O$ and BCP is their inability to differentiate Plasmodium spp. QBC and BCP fluorescent methods are more demanding technically. QBC method requires a special centrifuge tube and the cen- trifuge whereas $\mathrm{BCP}$ method requires a special dye, which is not easily available and fluorescent microscope with high intensity mercury and halogen lamp. In spite of their limitations including the requirement for special staining, expensive equipment, the fluorescent microscopy for rapid detection of malarial parasite in blood is a viable alternative to examination of Giemsa stained smear.

Another approach to the laboratory diagnosis of malaria is based on the detection of nucleic acid sequence specific to Plasmodium species using PCR technique. This technique can permit species specific diagnosis of Plasmodium infection and can also detect mixed infection [19]. The major advantage of using a PCR based technique is in its ability to detect infection in patients with as low a parasitemia as 5-parasites $/ \mu \mathrm{l}$ with $100 \%$ specificity [20]. However this technique is expensive and labour intensive, requires extensive technical expertise, involves multiple steps and cannot be used to distinguish between viable and non-viable organism. PCR inhibitors naturally present in blood samples may result in significant number of false negative results. False positive results due to carrying over contamination have also been recorded [20].

The new generation antigen captive tests are capable of detecting fewer parasites and of producing a result more rapidly and one such test, reported to have the ability to distinguish viable from non-viable parasites appears to be a promising tool for monitoring therapy with anti-malarial drugs. There are two parasite antigens currently used in the new, rapid diagnostic tests: the Histidine Rich Protein-2 [HRP-2] which is only produced by Plasmodium falciparum $[(21,22]$ and the parasite lactate dehydrogenase (pLDH) antigen produced by all four species infecting man. Both these antigens are secreted into the blood by all asexual stages of the parasite. The pLDH is also produced by gametocytes [23]. The antigen capture tests are rapid and simple to perform and have detection limits comparable with those of high quality microscopy, that is, 100-200 parasite/ $\mu \mathrm{l}$ [24,25]. Gupta et al, in their study, using the HRP-2 antigen captive immunochromatographic test found sensitivity and specificity as $87.5 \%$ and $100 \%$ respectively [26]. QBC assay and antigen captive test can be recommended as first line diagnostic choice for malaria where as utility of species specific PCR is in diagnosis of falciparum malaria more so when accompanied by its complications [27]. They are particularly useful for studies of strain differences, mutations and genes involved in drug resistance rather than for routine diagnosis. The most promising diagnostics are serological dip- tick tests which are 
commercially available like ParaSight F ( Becton Dickinson India Pvt Ltd.), Paracheck ( Orchid Biomedical System), ICT Malaria-Pf and Pv (AMRAD -Australia) and Rapid-MP( Biolab Diagnostics) the HRP-2 based tests and OptiMAL test based on detection of pLDH.

Thus with the availability of wide range of modalities for diagnosis of malaria today, perhaps the time has come to review different newer methods and status of Giemsa stained blood smear as gold standard for diagnosis of malaria may be revised.

\section{REFERENCES}

1. Wyler D J. Plasmodium and Babesia. In : Gorbach S L, Bartlett J G, Blacklow N R, editors. Gorbach Bartlett Blacklow's Infectious Diseases. $2^{\text {nd }}$ ed. Philadelphia : W B Saunders, 1998: 2407-20.

2. Gilles H M. Historical Outline. In : Gilles H M, Warrell D A, editors. Bruce-Chwatt's Essential Malariology. $3^{\text {rd }}$ ed. London : Edward Amold, 1993: 1-11.

3. Park K. Park's Text Book of Preventive and Social Medicine. $15^{\text {th }}$ ed. Jabalpur (India) : Banarsidas Bhanot, $1997: 188$ 202.

4. Gilles H M. Diagnostic Methods in Malaria. In : Gilles H M, Warrell D A, editors. Bruce-Chwatt's Essential Malariology. $3^{\text {rd }}$ ed. London : Edward Arnold, 1993: 124-63.

5. Park K. Park's Text Book of Preventive and Social Medicine. $16^{\text {th }}$ ed.Jabalpur (India) : Banarsidas Bhanot, $2000: 189-99$.

6. Burman S N. Malaria - an overview. J Ind Med Assoc 2000; $98: 632-37$.

7. Butler D. Time to put Malaria control on global agenda. Nature $1997 ; 386: 609-12$.

8. WHO. A rapid dipstick antigen capture assay for the diagnosis of falciparum malaria. Bull of WHO $1996 ; 74: 47-54$.

9. Warhurst D C, Williams J E. Laboratory diagnosis of Malaria. J Clin Pathol 1996 ; 49 : 533-8.

10. Nlabandin R M, Sammons D W, Manley M, Xie L, Sterling C R, Egen N B, Glingras B A. A molecular based magnet test for Malaria. Am J Clin Pathol 1995 ; 103 : 57-64.

11. Baird J K, Purnomo, Jones T R. Diagnosis of Malaria in the field by fluoresence microscopy of $\mathrm{QBC}$ capillary tubes. Trans R Soc Trop Med Hyg $1992 ; 86$ : 3-5.

12. Benito A, Roche J, Molina R, Amela C, Alvar J. Application and evaluation of QBC Malaria diagnosis in a holoendemic area. Applied Parasitol $1994 ; 35$ : 266-72.

13. Gay F, Traore B, Zanoni J, Danis M, Fribourg-Blanc A. Direct Acridine Orange fluorescence examination of blood slides compared to current techniques of malaria diagnosis. Trans R Soc Trop Med Hyg 1996 ; 90 : 516-8.

14. Clendennen T E, Long G W, Baird J K. QBC and Giemsa stained thick blood films : Trans R Soc Trop Med Hyg 1995 ;
$89: 183-4$.

15. Kawamoto F. Rapid diagnosis of Malaria by Fluorescence microscopy with light microscopy and interference filters. Lancet 1991 ; i : 200-2.

16. Lowe B S, Jeffa N F, New L, Pedersen C, Engbaek K, Marsh $\mathrm{K}$. Acridine orange fluorescence techniques as alternatives to traditional Giemsa staining for the diagnosis of Malaria in developing countries. Trans R Soc Trop Med Hyg 1996 ; 90 : 34-6.

17. Makler M T, Ries L K, Ries J, Horton R J, Hinrichs D J. Detection of Plasmodium falciparum infection with the fluorescent dye benzothiocarboxypurine. Am J Trop Med Hyg $1991 ; 44: 11-6$.

18. Cooke A H, Moody A H, Lemon K, Chiodini P N, Horton J. Use of the fluorochrome benzothiocarboxypurine in Malaria diagnosis. Trans R Soc Trop Med Hyg 1992 ; $86: 378$.

19. Barker R H (Jr). DNA probe diagnosis of parasitic infections. Exp Parasitol 1990; 70 : 494-9.

20. Kawamoto F, Miyake H, Kaneko O, Kimura M, Nguyen Q, Liu T D, Zhou M, Le D D, Kawai S, Isomura S, Wataya $Y$. Sequence variation in the $18 \mathrm{~S}$ rRNA gene, a target for PCR based Malaria diagnosis, in Plasmodium ovale from Southern Vietnam. J Clin Microbiol 1996 ; 34 : 2287-9.

21. Howard R J, Uni S, Aikawa M, Aley S, Leech J H, Wellems T E, Rener J, Taylor D W. Secretion of malarial histidine rich protein (Pf HRP-2) from Plasmodium falciparum infected erythrocytes. J Cell Biol 1986 ; 103 : 1269-77.

22. Rock E P, Marsh K, Saul S J, Wellems T E, Taylor D W, Maloy W L, Howard R J. Comparative analysis of the Plasmodium falciparum histidine rich proteins HRP-1, HRP-2, HRP-3 in malaria diagnosis of diverse origin. Parasitology $1987 ; 95: 209-27$.

23. Oduola A M J, Omitowoju G O, Sowunmi A, Makler M T, Falade C O, Kyle D E, Fehintola F A, Ogundahunsi A O T, Schuster B G, Milhous W K. Plasmodium falciparum evaluation of lactate dehydrogenase in monitoring therapeutic response to standard antimalarial drugs in Nigeria. Exp Parasitol 1987 ; 87 : 283-9.

24. Dietz R, Perkins M, Boulos M, Luz F, Reller B, Corey C R. The diagnosis of Plasmodium falciparum using a new antigen detection system. Am J Trop Med Hyg 1995 ; 52 : 45-9.

25. Palmer C J, Lindo J F, Klakala W, Quesada J, Caminsky R, Ager A L. Evaluation of the optiMAL test for rapid diagnosis for Plasmodium vivax and Plasmodium falciparum Malaria. J Clin Microbiol 1998 ; 36 : 203-6.

26. Gupta M K, Misra R N, Chawla N, Mani H, Chowdhry C N, Singh SP, Gupta S. Immunochromatographic test : A New dimension in diagnosis of Plasmodium falciparum Malaria. MJAFI 2001; $57: 188-90$

27. Chander Yogesh, Basu B, Nagendra A, Ohri VC, Mohan Chand R. PCR in species specific diagnosis of malaria in comparison to currently available methods. Armed Forces Medical Research Committee Project No 2204/98.

This Journal is indexed/abstracted by ExtraMED, Index Medicus for Southeast Asia, International Abstracts of Biological Sciences, Abstracts of World Medicine, IndMED, Hygiene and Tropical Disease Abstracts and EMBASE. The IndMED database is accessible on Internet at the Website http://basis.delhi.nic.in/nd Guidelines for authors appear in the January issue every year. 